\title{
Consistency and Law Comparison in Consumer Protection Law Design in the Light of the Socially Responsible Market Economy Approach
}

\author{
Stefan Koos* \\ Department of Economics and Management, Universität der Bundeswehr Munich, Germany
}

* stefan.koos@unibw.de

\begin{tabular}{l}
\hline Article Info \\
\hline Received : 2021-04-10 \\
Accepted : $2021-06-07$ \\
Published : 2021-07-30 \\
\hline
\end{tabular}

Key words: consumer protection, socially responsible market economy, legislative, legal development, social-functional approach, social state principle

\begin{abstract}
Social justice is an essential issue in the development of Indonesian law of the 21st century. Consumer protection is an aspect of social justice because it maintains "equality of arms" between suppliers and consumers. The more technological developments are integrated into social life and thus also into the business competition process, the greater the importance of consumer protection becomes, because the use of disruptive technologies, for example artificial intelligence, can shift the balance between providers and consumers in favour of economically strong providers. This will lead to the need to redefine the position of consumer protection in the Indonesian legal system. Law No. 8/1999 on Consumer Protection in its current form follows a rather ambiguous systematic approach by not clearly distinguishing between individual and social-functional protection purposes of consumer protection. The article argues for creating the methodological framework for a possible revision of the Indonesian consumer protection law with a strong integration of culturalempirical and scientific-systematic viewpoints.
\end{abstract}

\section{INTRODUCTION}

Topics related to social justice nowadays are frequent in conferences on social science and humanities in Indonesia. An important aspect of this is the question of legal structures that effectively and consistently promote social balance and effectively implement the social responsibility of the state. Law design, law enforcement and their connections with the interdisciplinary question of social justice are crucial factors for the development of a society and the more the economic development of Indonesia proceeds, the more the questions for the modernization of the law in the light of the internationalization arises.

However, the development of law through the adoption of foreign legal norms is problematic if it is not carried out consistently and if it is not accompanied by basic academic research. This leads to a methodological problem in some comparative law studies. It is not uncommon for legal norms to be compared and for the adoption of certain norms into one's own legal system to be advocated on the basis of the comparison. In doing so, differences in the historical, cultural, social and economic conditions of the states are often not sufficiently taken into account. The method of comparative law is an essential instrument of future legal reforms, but it requires an extensive interdisciplinary research approach, which may also require empirical studies. The consequence of the introduction of insufficiently adapted legal norms can be an erosion of the acceptance of the norms in social reality and a far-reaching inconsistency of the legal system, especially if the substantive legal situation is not accompanied by functioning instruments of law enforcement.

Using the example of the Indonesian Law No. 8/1999 on Consumer Protection and the EU's General Data Protection Regulation, these aspects will be highlighted in the following. The paper seeks to promote scientificity, interdisciplinarity and cultural relevance in future legal designs. 


\section{LITERATURE REVIEW}

The social-functional approach of the consumer protection law in the German and European unfair competition law and the understanding of the competition as an evolutionary process a "responsible market economy" ("Verantwortete Marktwirtschaft") was elaborated by Fezer Invalid source specified. based on his theory of a pluralistic subjective rights concept Invalid source specified. which postulates an integrated limitation to economic power by social responsibility within the subjective right of the legal person. This view is relevant for the theory of a social-functional approach of the competition law and of the protection of the collective interests of consumers as a market functional protection aspect. The approach is based on the doctrine of Ulmer (1932 \& 1937) who founded the model of the integration of consumer protection, general public interest and concurrent interest within a competition protection system. Following the doctrine of Hefermehl Invalid source specified. the purpose of the unfair competition law is not only the protection of individual subjective rights of the competitors (i. e. as protection of an individual right to undisturbed business) but the reaction to infringements of objective norms of behaviour and therefore the protection the competition as institution. I was describing competition law motivated consumer protection in this sense as a relevant factor of social justice in Indonesia (Koos, 2015 \& 2017). Based on this the social-functional approach was linked to the situation of the consumer protection law in Indonesia Invalid source specified.. Additionally, I applied the social-responsibility approach to the international business law Invalid source specified..

\section{METHOD}

This paper is an augmented and adapted version of my presentation at the $1^{\text {st }}$ International Conference on Social Science and Humanities in Bangladesh on $2^{\text {nd }}$ April 2021. It picks up considerations from my research on the reception of a social-functional approach to consumer protection law in Indonesia and the status of consumer protection law in Indonesia and applies them to the method of legal development. The basic method of the research is literature analysis.

\section{DISCUSSION}

Consumer protection law is concerned with social justice: it affects the welfare of the society as it balances an aspect that arises from the information gap and from the power gap between entrepreneurs and consumers. Consumer protection law is thus an important area in which the state assumes its responsibility for society in a market-based economic system. Moreover, the degree of informedness of consumers in a state seems to be congruent with the degree of legal and political sovereignty of citizens in the respective state.

Consumer protection is in parts an essential area of the competition law and therefore of the market law. Market Law must be understood in its relevance for the social development. Only sovereign, well informed and not deceived or threatened consumers can make adequate product choice decisions within the market process. If consumers are collectively uninformed, misled or otherwise manipulated, then suppliers are unable to effectively enforce entrepreneurial performance in the market because consumers may not identify the better offer (Koos, 2017). This leads to wrong incentives in the market. Competition then cannot fulfil its distribution function. Consumer protection is thus an element of economic law that is particularly linked to social development in a state.

According to Fezer (1986a and 1990) economic power in the approach of a socially responsible and socially based economic law, exercised through self-interested subjective law corresponds necessarily with an increased degree of social responsibility, which immanently (within the subjective law position of the market actor) restricts the scope of freedom of market actors. 
This is an approach which is conform with the constitutional order of the Federal Republic of Germany: Article 20 par. 1 ("sozialer Bundesstaat") and Article 28 par 1 ("Sozialer Rechtsstaat") of the German Constitution ("Grundgesetz") stipulate that the Federal Republic of Germany is a "Sozialstaat" (welfare state). The Sozialstaat principle is historically based, on the one hand, on certain Christian moral concepts that persisted in the secularised state and, on the other hand, on the demands of the workers and revolutionary movements in the 19th century. It was developed to its recent form through the various modern constitutions and through the jurisdiction of the Federal Constitutional Court "Bundesverfassungsgericht" (King, 2014:25). In German constitutional law, the social state principle is a postulate in need of fulfilment as a state objective (Heinig, 2019:1889), from which state duties to protect and citizen rights of participation are derived. The state fulfils the obligation arising from the social state principle by shaping the legal system in the light of an active and socially just social policy and intervening with it in the economy. In this sense, the social state principle serves as a legitimisation of the state's intervention in economic freedom, without entitling the state to establish a total socialist market order Invalid source specified. or to maintain a given social status quo (Heinig, 2019:1889).

The principle comprises two basic elements: On the one hand, it contains the element of social security, which concerns, for example, the safeguarding of a subsistence level of the citizenInvalid source specified. or the protection of the citizens in case of illness. On the other hand, social justice is the content of the principle of the social state. This covers issues such as labour law, tenancy law, equal treatment and consumer protection law. The state's obligation to social justice, in conjunction with the legitimation to intervene, leads to the legislative restriction of areas of freedom of economic participants, for example by restricting the termination of employment contracts and tenancy agreements, and to limitations of the freedom of market participants in the interest of protecting consumers. This results in the state's duty to regulate economic development conform with the requirements of social justice - including the protection of consumers- but without devaluing the constitution's guarantee of freedom and property. This can be also interpreted as a basis of a socially responsible market economy.

\section{Two fundamental requirements for legal design seem important:}

1. Legal norms should not be based solely on economic efficiency but should be integrated into a pluralistic canon of legal principles and methods Invalid source specified., keeping the legislative process open and taking into account various social and cultural aspects. As Fezer (1986b \& 1988) states, the economic analysis of law is not compatible with a pluralistic doctrine of law. This view is to follow for the case that the economic analysis of law is seen as the dominant method to find out about the suitability and effectiveness of a legal design Invalid source specified.. The absolute dominance of economic effectivity approaches would be a contradiction to pluralistic legislative methods.

2. The design of law should primarily strive to create incentives for socially responsible acting by market actors and citizens and secondarily be based on prohibitions and sanctions.

The aspect of the immanent restriction of the freedom of market actors thus requires that law must create incentives to behave in a legally compliant manner. Every subjective right contains the aspect of social responsibility. Stronger economic power leads to stronger social responsibility. This may be a relevant point also for the development of the theory of corporate social responsibility (CSR). Compared to an approach, which limits freedom from outside the subjective right, in this approach the limitation of the freedom is integrated into the interpretation of the subjective right itself. Social responsibility and legal duties are congruent in a certain way in this approach.

In order to create incentives for compliant (socially responsible) behaviour, compliance should therefore be worthwhile for market actors and legally compliant market actors must not meet negative effects arisen from their compliant behaviour. An effective legal system should 
create and maintain such an environment. However, compliance is not worthwhile for market actors if the state regulations can be easily circumvented by other market actors, because the market actor behaving in a law-abiding manner then has higher transaction costs due to compliance with legal standards than the one who breaks the law.

Corruption, as an example, is based, among other things, on political structures, such as the legal control setting or transparency, but also on certain cultural factors, such as strong identification with family or social groups and local background coming with a relatively low identification with an existing supralocal state structures. Furthermore, as other relevant factors may be mentioned: traditionally strong hierarchies and a widely respected and applied seniority principle. Ultimately, however, the welfare-minimising problem of corruption is also caused by the existence of inconsistent legal systems that are not consistently enforced and thus offer loopholes for evasion. On the other hand, a legal system that seems to tolerate the illegal enrichment of individuals is perceived as unjust by society as a whole, undermining the lawabidingness of all citizens. If the public sector is characterised by corruption, individual citizens will also see no reason to behave law-abidingly when the opportunity arises. A legal system should create incentives for socially adequate behaviour; it must be worthwhile to behave lawabidingly. A well-designed law in a pluralistic social order fulfils a social control function not only by deterrence, but also by convincing citizens that compliance with the law is necessary to maintain social order and therefore is improving their own situation. This - of course - is to be understood only as an ideal model to be approached in the social reality.

On the one hand, this shows the importance of effective law enforcement for social welfare. On the other hand, it becomes clear that effective law design must take into account the social and cultural characteristics of a society, because law is then more likely to be perceived as part of social conviction.

\section{For the field of the consumer protection law and competition law in Indonesia, I would like to name three factors in this context:}

Firstly, future adaptations and amendments of the consumer protection law and of the unfair competition law should take into account cultural and economic characteristics of the society. This applies in particular to the adoption of foreign-inspired legal designs. As a visiting scholar from abroad, I am occasionally asked by colleagues in discussions at universities in Indonesia whether Indonesia should adopt certain pieces of legislation from Germany or the European Union. This question cannot be answered without a careful comparative law analysis. Comparative law, however, is much more than the comparison of legal situations of different legal systems. It requires a strong interdisciplinary and scientific research approach, which, in my experience, is sometimes lacking in comparative law doctorate dissertations in Germany and which might also be strengthened in the process of a reception of foreign legal models in Indonesia. Looking at the example of consumer protection, the academic development of a social-functional approach to the consumer protection law can only be a first step. The question of how such an approach can be integrated into the Indonesian legal system is a question that is far more difficult to answer and requires cross-disciplinary considerations, especially also empirical studies of the consumer situation. Consumer protection basically has two regulatory directions: on the one hand, the prevention of unfair consumer-damaging activities by suppliers and, on the other hand, the education of consumers. Social-functional consumer protection thus requires, in addition to a system of sanctions against infringements of consumer interests, an effective information model that strengthens the collective sovereignty of consumers and thus reduces the danger of infringements of consumer interests.

The appropriate balance between sanctioning violations and informing consumers differs in various countries depending on the social structure of their population. A consumer protection law which is only or mostly sanctioning may not have the desired effect if existing strong information gaps between consumers and suppliers - especially in rural areas - are not 
supplemented by a strong effective information concept. A predominantly sanctioning law is more likely to work in states with a high, rather homogeneous social or education level than in states with a heterogeneous educational structure or with strong differences between urban and rural populations. Before a reception of a respective consumer protection model possibly can take place, this should be carefully empirically examined.

Secondly, laws must be flanked by effective monitoring functions and an effective sanctioning system. Law No. 8/1999 on Consumer Protection, modern in itself, may not be implemented sufficiently effective in Indonesia Invalid source specified.. There may be a lack of adequately funded consumer protection organizations and of effective monitoring by competent authorities as well as an effective sanction system. A further problem is that consumers are very often unaware of their consumer rights, which leads back to the need of an effective information model. A consumer protection law which is not sufficiently enforced cannot fulfil its purpose to protect the sovereignty of the consumers. Flanking a scientific discussion on the systematic place of the consumer protection within the market regulation law, an 'inventory' of the practical problems of the Indonesian consumer protection law would be necessary. This should involve cultural aspects.

On the administrative level, the special hierarchical character of a society may play a role in this. Decentralization of control authorities may strengthen the effectivity of official action. But if it is not fully implemented, the principle of seniority may interfere with investigations at the decentralized level. In Germany, consumer protection is largely left to private law enforcement. This leads to certain other disadvantages, but it leads also to the fact that legal violations in the consumer protection area are quite effectively controlled. However, it is with good reason that the European Union has prescribed the substantive consumer protection law but has left the concrete procedural implementation up to the member states due to substantial cultural differences between the member states of the EU and due to different legal cultures. Private law enforcement alone may not be the right approach for Indonesia.

On the level of the material law the law No. 8/1999 is not differentiating the individual purpose of the consumer protection law from the market related purpose of the consumer protection law (Shidarta \& Koos, 2019:67). A clear differentiation and systematic definition of the protection goals of the consumer protection law may strengthen the social related aspects of the law.

Thirdly, law enforcement must be consistent. Inconsistency leads to a wide lack of respect for the law. In this respect, for some protection rules, a decision must be made as to which extent certain standards are actually desired by a society and to which extent standards can be realistically fulfilled given a certain cultural and economic surrounding. Certain inconsistencies can be found in every legal system. An example from the law of the European Union can be found in the European General Data Protection Regulation (GDPR), which follows a rather traditional regulation approach for the protection of personal related data of European citizens. Especially in the pandemic situation it became apparent that the strict prohibitive approach of the GDPR is very difficult or even impossible to reconcile with the current needs of practice in the digitalisation which is now to be expanded very quickly and increasingly, for example in school lessons and university teaching. US-American conferencing software may not be used as a tool in school lessons and university teaching as a matter of principle, because $\log$ data of the audience are stored on servers outside the EU which contradicts the GDPR. It is very difficult to conduct oral online examinations using such software in a legally compliant manner because the GDPR places extreme demands on the consent of examination candidates in processing their personal data. Another example in this context is the use of artificial intelligence in human resources management in companies, which relies on the use of large amounts of training data for the learning process of the AI. The GDPR's stringent requirements for employees' consent to the processing of their data for the purpose of AI training currently make it almost impossible to develop such systems in a 
globally competitive manner in Europe. Apart from the anti-innovation effect of such regulations, one can state as a matter of law that certain norms of the GDPR are broken regularly because no legally compliant alternative is seen by the actors. Without such potentially data protection law infringing software, online teaching is currently not possible in Germany. Since teaching must be maintained, the only option for users may be to break the corresponding data protection regulations.

This shows the effect of regulations that are not adapted to social reality: If legal norms cannot be implemented in practice, legal practitioners are forced, as it were, to circumvent the rules, interpret them extensively or break them openly. This leads to disadvantages for those legal practitioners who still observe the legal norm. On the one hand, this is a problem of the constitutional principle of equal treatment. Above all, however, negative incentives are set, which can ultimately either lead to the erosion of compliance with the law or - with strong state control and sanctioning of violations - have other negative effects. Legal rules must not force to inconsistent application.

An example of this in the Indonesian situation are certain food hygiene rules. If we look at certain countries, we find strictly regulated food hygiene systems, which has led to street food being largely concentrated in certain verifiable areas. For a country like Indonesia with a rich street food culture, there are two options if a legislator wanted to introduce an internationally adapted food hygiene law:

Or the state consistently implements such a law inspired by other countries. This could lead to a profound change in the living culture of the local population, because consistency implies that not only stationary restaurants, but also small street food entrepreneurs are bound by such rules. Compliance with strict hygiene regulations might not be economically feasible for such entrepreneurs. Or the state may introduce corresponding standards but then apply them in a pragmatically discriminatory manner and regularly refrain from inspecting small street food businesses. If this is not done in a legally compliant manner, for example by clearly defining justified exceptions within the legal rule, regulation becomes inconsistent. With regard to the aspect of cultural adaptation, the formulation of certain reasoned exemptions and certain feasible requirements for defined small entrepreneurs would be preferable in the Indonesian legal situation.

\section{CONCLUSION AND SUGGESTION}

Inconsistent legislation in all states is often the result of an insufficiently interdisciplinary or insufficiently scientific preparation within the legislative process. Without having done already a detailed empiric research in Indonesia on the consumer perception of advertisement in different regions of the Indonesian archipelago it is obvious that the adaption of foreign consumer protection instruments needs a careful review on cultural and economic aspects in order to create a consumer protection law which is acknowledged by the market participants and which realistically can be applied and enforced consistently. This requires also the decision on the status of the consumer protection within the system of the Indonesian law and therefore a systematic discussion on the functions of the consumer protection law, namely on the differentiation between individual und social-functional protection goals.

\section{This leads to the following suggestions:}

Firstly, legislators should examine the legal system to see if they can find norms that are ineffective, not sufficiently enforced or insufficiently enforceable. The legal system should therefore be 'streamlined', as it were, which serves effectiveness and transparency and reduces redundancies and the danger of contradictory rules. Legal rules which are assessed as socially necessary should then be strongly integrated into a methodological and procedural context. This requires the stimulation of strong jurisprudential-methodological research through the promotion of law faculties and the support of interdisciplinary research projects of universities. 
Secondly, science and state institutions should cooperate in an interdisciplinary manner in the development of the legal system in order to achieve the best possible adaptation of new legislation to the cultural and social characteristics of the country. Here, the increased promotion of corresponding comparative law research within the framework of the faculties of law, economics and political science will be helpful.

Thirdly, the aspect of political and social education should not be disregarded. Citizens need to know how law works and what it means, which rights they have and how those rights can be enforced. A consumer who is unaware of his or her consumer rights is not in the interest of effective law enforcement and the consumer protection law then fails to achieve its welfareenhancing goals.

Universities should furthermore encourage students, who will become the future leaders of the country, to critically question traditional dogmas and legal customs. This partly requires a cultural rethinking: I have repeatedly experienced in Universities that students do not dare to contradict a professor on a technical level and do not even dare to express their own divergent ways of thinking after being explicitly asked to do so. In my observation, the extent to which critical thinking and the ability to debate beyond the traditional social rules of respect for older or higher-ranking persons are prevalent among students depends on the vision and mission of the universities. However, without critical thinking and self-awareness, the budding scientists and functionaries will not be competitive in the global scientific world.

A certain skepticism of the future legal experts should extend especially to the uncritical adoption of foreign legal experiences. Students should certainly be shaped cosmopolitically, but they must not forget the cultural roots of the society in which they will apply and influence the legal system. This does not mean the propagation of any uncritical 'legal patriotism' but a certain awareness of social reality. Law itself is culture. Global law is cosmopolitan, but the national law - and also the integration of globalized regulation goals into the national law - still need a certain basis in the cultural background to be effective. Regulation goals which are adapted to disruptive and globalized aspects of the modern society, such as the regulation of the token-economy, the use of artificial intelligence or the data protection in the internet, on the other hand, of course cannot be orientated only on local traditions. The more ubiquity actually displaces traditional territoriality, the less specific national solutions will be adequate. However, there are still areas of regulation which are connected to the local aspects of life in a state.

\section{REFERENCES}

Bundesverfassungsgericht, 1 BvB 2/51 (1956, August 17), BVerfGE 1956, p. 198 (German language only). https://opinioiuris.de/entscheidung/847\#II.__Die_Auslegung_des_Art._21_Abs._2_GG (visited April 9, 2021).

Bundesverfassungsgericht, 1 BvL 10/101 (2012, July 18). https://www.bundesverfassungsgericht.de/SharedDocs/Entscheidungen/EN/2012/07/ls20120 718_1bvl001010en.html (visited April 9, 2021).

Fezer, K.-H. (1985). Die Pluralität des Rechts. Juristenzeitung (JZ), S. 762-771.

Fezer, K.-H. (1986a). Teilhabe und Verantwortung. Munich: C.H.Beck.

Fezer, K.-H. (1986b). Aspekte einer Rechtskritik an der economic analysis of law und am property rights approach. Juristenzeitung (JZ), S. 817-824.

Fezer, K.-H. (1988). Nochmals: Kritik an der ökonomischen Analyse des Rechts. Juristenzeitung (JZ), S. 223-228.

Fezer, K.-H. (1990). Verantwortete Marktwirtschaft. Juristenzeitung (JZ), S. 657-663. 
Consistency and Law Comparison in Consumer Protection Law Design in the Light of the Socially Responsible Market Economy Approach

Hefermehl, W. (1955). Der Anwendungsbereich des Wettbewerbsrechts. In R. Dietz, A. Hueck, $\&$ R. Reinhardt, Festschrift für Hans Carl Nipperdey (S. 283-301). Munich/Berlin: C.H.Beck.

Heinig, M. (2019, March 6). The Political and the Basic Law's Sozialstaat-Principle Perspectives from Constitutional Law and Theory. German Law Journal - Cambridge University Press, pp. 1887-1900. https://www.cambridge.org/core/journals/german-lawjournal/article/political-and-the-basic-laws-sozialstaat-principleperspectives-fromconstitutional-law-and-theory/874F28B706F3522B1AA45221CA8A5F0B (visited April 9, 2021).

King, J. (December 2014). Social Rights, Constitutionalism, and the German Social State Principle. e-publica - Revista Electrónica de Direito Público, S. 19-40. https://www.epublica.pt/volumes/v1n3/pdf/Vol.1-N³-Art.03.pdf (visited April 9,2021).

Koos, S. (2015). Core Elements of Social Justice from the Competition Law Perspective. DAAD International Workshop "Justice for All" (S. 1-14). Jakarta: Faculty of Syariah and Law, Universitas Islam Negeri.

Koos, S. (2016). Global Responsibility and International Mutual Consideration in the Business Law. Conference Proceedings. Konferensi ke-6 Asosiasi Filsafat Hukum Indonesia: "Antinomi Hukum - Pluralisme ataukah Integrasi", (S. 21-28). Bandung.

Koos, S. (2017). Ethic and Social Responsibility in the Competition Law. International Conference on Developing a Legal System to Promote Social Welfare. Jakarta: Faculty of Law, Trisakti University.

Shidarta, S., \& Koos, S. (2019). Introduction to a Social-Functional Approach of the Indonesian Consumer Protection Law. veritas et justitia, S. 49-79. https://journal.unpar.ac.id/index.php/veritas/article/view/3292 (visited April 9, 2021).

Ulmer, E. (1932). Sinnzusammenhänge im modernen Wettbewerbsrecht. Berlin.

Ulmer, E. (1937). Wandlungen und Aufgaben im Wettbewerbsrecht. Gewerblicher Rechtsschutz und Urheberrecht (GRUR), S. 769-773. 